\title{
Accountability mechanisms in international climate change financing
}

\author{
Rishi Basak $^{1,2}$ (D) Edwin van der Werf ${ }^{3,4}$ (D)
}

Accepted: 17 April 2019 / Published online: 30 April 2019

(c) The Author(s) 2019

\begin{abstract}
This paper uses agency theory to analyse the incentives that a donor (principal) and recipient (agent) face as actors in an accountability regime for the financing of international climate change projects in developing countries. We address the following question: What accountability measures serve to align the incentives of the donor with those of the recipient in climate change financing? We focus on the relationship between the Green Climate Fund as a donor and one of its Accredited Entities as a recipient. We examine the consequences of misaligned incentives and asymmetric information, looking at a specific set of accountability measures, including performance indicators, penalties for poor performance, as well as the role of pressure exerted by civil society organisations (CSOs). We find that the use of imperfect performance indicators can reduce the risk of project failure if they are strongly correlated with adaptation and mitigation impacts. Penalties can have a positive impact on project outcomes, but impose risks upon the agent, which could lead him to refuse the contract for the implementation of the climate change project. The pressure of CSOs was found to have the potential to motivate donors and recipients to become more efficient and effective in their delivery of projects but could also lead to the donor choosing to finance lower-risk projects with fewer climate change benefits. We suggest that accountability requirements need to be carefully balanced with other objectives, including having a diverse set of entities willing to bid for the delivery of projects.
\end{abstract}

Keywords Principal-agent problem · Information asymmetry $\cdot$ Accountability $\cdot$ Climate finance $\cdot$ Performance indicators · Civil society organisations · Green Climate Fund

Rishi Basak

rishi.basak1@gmail.com

Wageningen University, Wageningen, The Netherlands

2 International Maize and Wheat Improvement Center, Km., 45 Carretera Mexico Veracruz El Batan, Texcoco, Mexico

3 Environmental Economics and Natural Resources Group, Wageningen University \& Research, P.O. Box 8130, 6700 EW Wageningen, The Netherlands

4 CESifo, Munich, Germany 


\section{Introduction}

The work program for long-term climate finance under the United Nations Framework Convention on Climate Change (UNFCCC) has set a goal of raising at least $\$ 100$ billion per year by 2020 (UNFCCC 2014). This goal was reiterated at the 21 st Conference of the Parties of the UNFCCC (COP 21) held in Paris in December 2015, where 195 nations signed the Paris Agreement. In the accompanying COP decision, it was decided that "... prior to 2025 the Conference of the Parties serving as the meeting of the Parties to the Paris Agreement shall set a new collective quantified goal from a floor of USD 100 billion per year, taking into account the needs and priorities of developing countries..." (UNFCCC 2015, p. 7). The Green Climate Fund (GCF) was established by the UNFCCC Conference of the Parties at its sixteenth session held in Cancun in 2010 (UNFCCC 2011) with the intent that it plays a key role in mobilising and allocating climate finance to developing countries so that they can mitigate and adapt to climate change. The GCF received a vote of confidence in Katowice at COP 24, as its funding replenishment was endorsed by conference attendees (UNFCCC 2018).

Expectations about the implementation of the Paris Agreement are high, especially with respect to the financing mechanisms for climate change mitigation and adaptation in developing countries. ${ }^{1}$ One of these "great expectations" is that a strong set of accountability regimes be put in place to manage the allocation of these significant sums (Abbott and Gartner 2011; Bird et al. 2011; van Kerkhoff et al. 2011). The term "accountability regimes" is used here to describe the systems of management that are put in place to ensure accountability, where accountability is construed as: "(A) relationship between an actor and a forum, in which the actor has an obligation to explain and to justify his or her conduct, the forum can pose questions and pass judgement, and the actor may face consequences." (Bovens 2007, p. 450). Ultimately, accountability regimes serve to legitimise the institutions involved (Kersbergen and Waarden 2004) and are often taken as a proxy for good governance (Dubnick 1998).

Similar and related to the role of the enforcement of property rights, accountability regimes allow economic actors to transact in a way that better satisfies all actors involved and help provide added certainty to transactions by spelling out expectations, roles and responsibilities, as well as mechanisms to give account and face consequences for not complying with agreed-upon objectives. The impact of accountability regimes on achieving desired objectives has been documented in studies in various fields, with varying results. For instance, Anderson and Feder (2004) looked at accountability issues pertaining to agricultural extension workers in developing countries. They found that extension workers were held accountable for the budget they spent and other activity-level indicators, but were not accountable for making sure that their programs benefited farmers, leading to poor program performance. Similarly, the World Bank (2004) found that service delivery failures in developing countries were related to weak accountability and that this was negatively impacting the poor, while Winters (2010) provides evidence that aid allocated to developing countries with stronger accountability regimes is more effective.

In this paper, we study the incentives that donors and recipients face in the financing and implementation of climate change mitigation and adaptation actions in developing

\footnotetext{
1 For an overview of international climate finance, see the Special issue of International Environmental Agreements: Law, Politics and Economics titled "Managing fragmentation and complexity in the emerging system of international climate finance" (Pickering et al. 2017).
} 
countries as actors in an accountability regime. The "donor-recipient" relationship analysed in this paper is focused on the relationship between the GCF and one of its so-called "Accredited Entities" responsible for implementing climate change adaptation and mitigation projects on the GCF's behalf. ${ }^{2,3}$ Key in the relationship between the donor and the recipient is that the former cannot directly observe the latter's actions; it can only observe the project outcome. As a result, the recipient may try to follow his own objectives, which may not be aligned with the objectives of the donor.

This paper therefore addresses the following question: What accountability measures serve to align the incentives of the donor with those of the recipient in climate change financing? In order to answer the question, we use the framework of principal-agent theory (see e.g. Laffont and Martimort 2009; Mas-Colell et al. 1995) to describe the relationship between the donor (principal) and the recipient (agent), how their incentives are misaligned, and to assess the impact of various accountability measures introduced in climate change financing modalities. We will argue that such measures come at a cost and may create adverse outcomes. The principal-agent framework also allows us to determine the potential impact of certain agent characteristics, such as their prudence and risk preferences, on the donor-recipient relationship. This is in keeping with other authors, such as Steinberg (2010), Kluvers and Tippett (2010) and Haque (2014), who have looked at accountability relationships in public administration using agency theory. ${ }^{4}$ Although other authors have used agency theory to describe issues related to international aid, international environmental assistance and climate finance, the focus of their research differs from that of this paper: some have looked at the relationship between aid flows and development outcomes and found that country ownership and aid allocation based on monitorable results are key ingredients of success (Bourguignon and Sundberg 2007); others put their attention to transaction costs and found that these can potentially reduce the effectiveness of climate finance, especially when project implementation is delegated to third parties via multilateral organisations (Brunner and Enting 2014). Similarly, donor country delegation of foreign aid distribution to international institutions has been analysed and it was found that the approach can be beneficial to reassure voters in the donor country that money is being spent judiciously (Milner 2006). Another study analysed the allocation of aid funding towards climate change projects and found that politico-economic factors play an important role in how such flows are reported (Michaelowa and Michaelowa 2011). Our paper builds on the extant literature by offering insights into the specific accountability measures found in international climate change financing institutions.

\footnotetext{
${ }^{2}$ In order to receive project implementation funding, interested agents are required to undergo an accreditation process to ensure they meet fiduciary and other standards (GCF 2017). A similar process is in place for the accreditation of Global Environmental Facility Project Agencies (GEF 2012) and Adaptation Fund Implementing Entities (Adaptation Fund 2018). Accredited Entities can be small developing country private sector firms or non-profit implementers, as well as large international organizations. The latter represent the majority of entities that have received GCF accreditation to date.

${ }^{3}$ Examples of projects that could be financed by the GCF include: improving fertilizer management practices (to reduce GHGs) and adopting drought-resistant wheat varieties (increasing resilience to climate change); reforestation of marginal lands to sequester carbon dioxide, foster groundwater recharge and reduce soil erosion; climate-proofing roads (i.e. to reduce erosion and impacts from heavy rains and floods) and reducing the carbon footprint of the transportation sector (e.g. via fuel efficiency, electric vehicles and various traffic management strategies).

${ }^{4}$ For an overview of the contribution of principal-agent modeling to the study of accountability see Gailmard (2014).
} 
The remainder of the paper is organised as follows: the next section elaborates on the concept of accountability as a principal-agent relationship and describes the accountability issues stemming from the relationship between donor and recipient in international climate change financing. In the subsequent sections, we analyse three sets of measures that serve to align the interests of donors and recipients: in Sect. 3, we analyse the use of imperfect performance data, in Sect. 4 a system of penalties, and in Sect. 5 the use of informal accountability stemming from pressure from civil society organisations (CSOs). In Sect. 6, we provide concluding remarks and suggestions for policy-makers to improve the accountability relationship between donors and recipients in climate change financing, as well as areas for further research.

\section{Accountability as a principal-agent relationship}

In the following sections, we use agency theory to analyse the accountability issues stemming from the relationship between a donor and a recipient in international climate change financing, where the principal wants to ensure that the agent works towards the objectives that she sets out. In this section, we show how accountability between a donor and a recipient in climate change financing can be described as a principal-agent relationship. We first describe the role of asymmetric information in this relationship. We then use agency theory to describe the characteristics of the donor as a principal and of the recipient as an agent. We subsequently describe the role of project risk and risk preferences in the relation between a donor and a recipient.

\subsection{Asymmetric information in climate change financing}

As the definition from Bovens (2007) shows, accountability is a relationship between at least two parties - one giving account to the other. Principal-agent problems (also known as agency dilemmas and agency theory) occur when a "principal" (i.e. any person, organisation or other entity) uses an "agent" (again, any person, organisation or entity) to fulfil an action on her behalf. The dilemma occurs when the agent, who acts in self-interest, has motivations that are not well aligned with those of the principal and the principal cannot directly observe the agent's actions. Importantly, the agent's actions cannot be deduced from observation of an outcome (Laffont and Martimort 2009; Mas-Colell et al. 1995). These agency problems arise in multiple contexts where responsibility is delegated and are very likely to be present in the accountability relationship between donors and recipients in the context of international climate change financing, such as the GCF, Global Environment Facility (GEF) or Adaptation Fund providing project funding to an implementing agency. ${ }^{5}$ Principal-agent theory is a useful framework to analyse public accountability as it offers "a flexible framework for modelling innumerable variations in institutional arrangements and comparing their potential for inducing desirable behaviour by agents." (Gailmard, 2014, p. 2).

\footnotetext{
${ }^{5}$ Agency problems are widespread in various delegation and contracting contexts, including public sector service procurement, in aid and international organizations (Hawkins et al. 2006; McAfee and McMillan 1986; Soudry 2008).
} 
For the purposes of this paper, we assume that the principal is an international climate change financing institution, such as the GCF, and that the agent is an external implementing entity operating in the developing country where the project is to be implemented. Principal-agent relationships are characterised by delegation of responsibility by the principal to the agent and the problem of asymmetric information: the principal cannot observe the level of effort put into the project by the agent (i.e. a case of hidden action). In the case of international climate financing, this is not only because the project takes place in another country, but in general perfect monitoring of the recipient's actions by the donor is too expensive or technically unfeasible. One can postulate, as is done in most of the agency literature, that the incentives of the agent are not perfectly aligned with those of the principal. For example, a GCF Accredited Entity typically has multiple projects to work on, limited resources (staff, money) and may even have its own objectives (e.g. high salary levels for its staff or a large office building). Since the donor cannot perfectly observe how the recipient spends his resources, the recipient may want to put fewer resources in the project, and more in its other projects or objectives, than the donor would like. We must note that our analysis may not necessarily apply to all climate change financing cases, such as bilateral funding directly from a donor country to a developing country, as incentives and motivations may differ.

\subsection{Climate finance donors as principals}

In a traditional principal-agent model (Laffont and Martimort 2009; Mas-Colell et al. 1995), the principal uses a compensation scheme to incentivise her agent in achieving the principal's interests. For simplicity, and without loss of generality, we assume that the objective of the principal (donor) is successful completion of a project at lowest possible cost, and that the project can end up in only one of two states: success or failure. The principal aims to develop a compensation package that will maximise her expected utility. The principal's utility depends on the success of the project and the payments made to the agent (which is a cost to the principal). In turn, the success of the project is described by a probability distribution of external factors (which we describe below) and the level of effort of the agent. This principal-agent relation applies to many cases in the climate change financing context, where the donor has a pre-established amount for grants. ${ }^{6}$ The principal therefore needs to design an offer to the agent in a way that motivates him to exert a high enough level of effort to successfully complete the project, at a low level of compensation.

\subsection{Climate finance recipients as agents}

The agent is willing to undertake work for the principal if the expected utility from the work is at least equal to his reservation utility level. In the context of climate change financing, this means that a project should be financially feasible for a recipient and be more interesting than possible alternative projects-this is known as the "participation constraint" in principal-agent theory. ${ }^{7}$ As is well known in the literature on principal-agent

\footnotetext{
${ }^{6}$ It must be noted that there are also many instances where donors publish open calls for proposals with no specified grant amounts. In those cases, the initial compensation payment is proposed by the agent.

7 One can also think of the expected utility as being at least equal to the agent's opportunity cost and as having pecuniary and non-pecuniary aspects, as has been portrayed in the literature, such as Jensen and Meckling (1976).
} 
theory, if the principal were able to directly observe the agent's level of effort, then a firstbest incentive scheme could be put in place, whereby she could simply offer him a payment for the effort that maximises her expected utility, even when there is uncertainty about external factors affecting project outcomes (Laffont and Martimort 2009; Mas-Colell et al. 1995). However, it is difficult to imagine a set of circumstances in international climate change financing where the donor would have the ability to directly and perfectly observe the recipient's level of effort. This is indeed the crux of the principal-agent problem.

As noted above, we assume that the principal wants the agent to put in a high level of effort as this increases the probability of success of the project. The agent, on the other hand, will put in a level of effort that will maximise his own expected utility, which depends on the compensation package, the cost of his effort, and the probability distribution of local external factors (which we describe below). In addition to the contract having to be sufficiently interesting for the agent to accept it (the participation constraint described above), the contract should hence also induce the agent to put in a sufficiently high level of effort. This is the "incentive compatibility constraint" in principal-agent theory and affects the payments the agent receives (as specified in the contract) in case of a successful project and in case of project failure.

\subsection{The role of risk in the principal-agent relationship}

As other international assistance, climate change projects can be (and often are) influenced by outside factors such as political instability, safety and security; economic deterioration; natural disasters; humanitarian crises; cross-border tensions; quality of legal institutions and business norms; and corruption (OECD Development Assistance Committee 2014). These external factors can have a positive or negative impact on project outcomes and cannot be fully controlled by the agent's level of effort. In the remainder of this paper, we denote these factors as project risk or background risk. As in much of the agency literature (e.g. Laffont and Martimort 2009; Mas-Colell et al. 1995), we assume that the agent's increased level of effort decreases the likelihood of project failure, but that the external factors can nonetheless bring about failure, even at high effort levels. Conversely, low levels of effort increase the likelihood of failure, but external factors can bring about success, even at low effort levels. Due to asymmetric information, the agent can blame external factors for poor performance and take credit for good performance when external factors are responsible (see e.g. Gundimeda and Guo 2003; Mitchell and Parson 2001). Following the literature, we assume that the uncertainty about such external factors has a known probability distribution and that the expected utility of the principal and the agent are functions of this probability distribution.

The expected utility level an agent gets from a particular contract and probability distribution of external factors is determined by the risk preferences of the agent. Hence, risk preferences have an impact on the types of contracts that can be put in place between the principal and the agent (Laffont and Martimort 2009; Sinclair-Desgagné and Spaeter 2017). Agents differ in the amount of downside risk they are willing to bear (Kimball 1990). The level of downside risk aversion determines how much the agent will require in compensation to be subjected to an increased downside risk - the higher downside risk aversion, the higher the amount the agent will demand (Crainich and Eeckhoudt 2008; Modica and Scarsini 2005). As such, if an agent is highly downside risk averse, he will not be willing to accept a contract that includes a very low level of payment (or perhaps even a penalty) in case of project failure, as the downside risk is too much for him to bear, ceteris 
paribus. With an agent that is highly downside risk averse, the principal will be required to offer a very large compensation level to convince the agent to participate (i.e. the participation constraint has to be satisfied) and the resulting contract may contain little difference in compensation whether the project was a success or failure (Ligon and Thistle 2013). As such, it can be anticipated that the risk preferences of agents will be important in the context of climate change financing, where mitigation and adaptation outcomes are subject to significant background risk. Some agents would prefer not having too large a portion of their compensation payment contingent upon the achievement of success. This may have more severe consequences for smaller grantee organisations, as they are more likely to be risk averse (Audia and Greve 2006; Dobrev 2001), which could lead international climate change financing institutions such as the GCF to disproportionately fund larger, less riskaverse organisations. In cases where significant background risk is present (e.g. if a project is to be implemented in a fragile state with poor institutions and weak macroeconomic conditions), it may lead even large grantees to prefer contracts where there is little difference in compensation whether poor or high performance is achieved.

Throughout our analysis, we assume that the principal is risk neutral and that the agent is risk averse. A person who is risk neutral is indifferent between choices that have the same expected payoff, but different riskiness, whereas a risk-averse person would opt for the less risky option. Risk neutrality for the principal is a defendable assumption in the context of international climate change financing, as the organisations financing climate change projects, such as the GCF, are very large and well capitalised. They also finance large project portfolios to hedge against individual project risks. Agents, on the other hand, can include small, medium and large players that may have much more limited resources to "insure" against project failure. As such, they are more likely to be risk averse. ${ }^{8}$

\subsection{The role of accountability measures}

We have argued that a donor in climate financing can observe whether a funded project is a success or a failure, but typically cannot observe the actions of the recipient, and that a recipient may have objectives that are not fully aligned with the objectives of the donor. Furthermore, climate finance projects are typically subject to project risks, so a project can be a failure (success) despite high levels of effort by the recipient. In order to create incentives and influence the agent's behaviour in accordance with the objectives of the donor, the donor puts in place accountability measures. Section 3 will discuss the role of information and performance indicators in the principal-agent relationship between the climate change financing institution and the agent who implements the project. In Sect. 4, we discuss the role of penalties.

\section{Performance indicators as an accountability measure}

An important consideration in accountability relationships is that of the information available to the principal to ensure that she can hold her agent to account (Bovens 2007). When a donor makes an investment in a grant project or program, she requires information about

\footnotetext{
${ }^{8}$ Audia and Greve (2006) find evidence supporting the economic intuition that smaller firms are more risk averse. Similarly, individual risk aversion has been found to decrease as wealth increases (Shaw 1996).
} 
the performance of her investment, using various performance indicators and corresponding metrics (Adam and Gunning 2002; Morra-Imas and Rist 2009). The quality of the performance information, including performance indicators, will have a bearing on the decisions made by the various actors involved (Mosley et al. 2004; Holzapfel 2016), including the ability to hold actors to account.

If the principal cannot continuously look over the agent's shoulder to see how much effort he is expending (either because it is cost-prohibitive, or technically unfeasible), she needs to include some type of accountability measure to incentivise her agent to put in high effort, as the asymmetric information creates an opportunity for the agent to reduce his level of effort without the principal knowing. One way to indirectly gauge the agent's level of effort is via the imposition of a Monitoring and Evaluation System (MES). A MES would require the agent to develop performance indicators before signing the contract (and hence the start of the project) and the agent to report on these performance indicators to the principal during the project. The payment scheme for the agent is then based on the performance indicators. Based on the performance reports, the principal can adjust her expectations about successful completion of the project during the project implementation phase and decide to terminate the project if her expected utility after processing the information in the performance reports becomes negative. ${ }^{9}$

The project performance indicators could be at the activity, output and outcome levels, which is reflective of modern donor requirements and grant management practices (Adam and Gunning 2002; Crawford and Bryce 2003). The activity indicator represents a set of activities that the grantee has completed in the context of the implementation of the project financed by the donor (e.g. number of events organised, number of collaborations with partners, policy dialogues undertaken). The output indicator can be thought of as including items such as the number of people trained, or number of publications produced by the grant recipient. ${ }^{10}$ The outcome indicator could be composed of a metric for greenhouse gas mitigation (e.g. tons $\mathrm{CO}_{2}$-equivalent reduced) and adaptation (e.g. composite resilience index) and will most likely be construed as an imperfect indicator, as many authors have shown that climate change indicators, especially adaptation metrics, are difficult to obtain (Adger et al. 2005; Branca et al. 2012; Ebi et al. 2004; Engle 2011; Hall 2017). ${ }^{11}$

In modern aid project management, grantees are required to develop MESs that usually set out what indicators are to be used for project monitoring. In the case of the GCF, for example, this is set out in the Monitoring and Accountability Framework for Accredited Entities (GCF 2015). Once the MES is approved by the donor, the agent begins project implementation and collects data on the indicators. This information is then put into a progress report and shared with the donor, who in turn reviews and scrutinises the information therein.

\footnotetext{
${ }^{9}$ Here it is assumed that the reports are truthful, although there is evidence that this may not always the case (Ebrahim 2003a). False claims can be verified via audits, which incentivize the agent to be truthful (Dixit 2002).

${ }^{10}$ For further examples of activity-level and output-level indicators, as well as a good discussion on their appropriate design and use, see Bourne et al. (2000), Feltham and Xie (1994), Morra-Imas and Rist (2009), Schiavo-Campo (1999). It is important to avoid falling into the trap of choosing easily measurable (but not necessarily appropriate) indicators in order to please donors (Ebrahim 2003b).

11 Of course, as Gundimeda and Guo (2003) rightly point out, some climate change mitigation projects actually do not even require monitoring of greenhouse gas emissions once the project is in its implementation phase, such as solar photovoltaic or wind power projects.
} 
The development and implementation of the MES, including data collection and reporting, are costly to the agent, and the review and verification of the performance information are costly to the principal. In practice, in organisations such as the GCF, the principal faces the cost to undertake periodic evaluations, spot checks and audits to assess performance more thoroughly (GCF 2015). The principal is facing a trade-off when deciding on the set of performance indicators to be included in the contract. An additional indicator means more information for the principal about the project's progress, yet it also means higher costs for the principal as she will have to review more performance data. Furthermore, an additional indicator may imply higher costs for the agent (who has to provide the data and may adjust his effort level in response to an additional indicator), who in turn may demand more compensation.

It should be noted that the performance indicators may not be perfectly correlated with successful completion of the project (Feltham and Xie 1994). As noted, the payment scheme is based on the performance indicators. If an indicator is only weakly correlated with successful project completion, but gets high rewards in the payment scheme, the agent has incentives to put disproportional effort in this performance indicator, at the expense of indicators that have a stronger correlation with successful completion of the project. Hence, when designing the payment scheme, the principal should make sure that financial incentives are aimed at indicators that measure the biggest contribution to the project (Feltham and Xie 1994).

In sum, the principal needs to carefully balance the costs, benefits and quality of an indicator when deciding whether to include it in the payment scheme of the contract. Furthermore, as discussed in Sect. 2, the amount of risk sharing between the principal and agent is also contingent upon the risk preferences of the agent, which has implications for indicator selection. Feltham and Xie (1994) showed that the more risk averse the agent, the more important it is to align indicators and the project outcomes, as indicators that are poorly related to a successful project outcome fail to incentivise the risk-averse agent to expend higher effort levels.

\section{Penalties as an accountability measure}

In addition to the MES, donors can impose penalties on grant recipients with unsatisfactory performance (Binnendijk 2000; Collier et al. 1997). Penalty schemes, especially of a financial nature, are more commonplace in climate finance, compared to traditional aid, as they have been "normalised" under the Kyoto protocol (Heal 2000) and perhaps because there is a larger number of non-traditional players involved (e.g. commercial banks). For instance, when the GCF funds projects, it has the ability to withhold payments, downgrade or withdraw an entity's accreditation status, or "blacklist" poor performers (i.e. rendering them ineligible for further funding and informing other donors of their poor performance) (GCF 2015). In certain cases, "claw-backs" on the grant payment can be exercised, that is, the donor may ask for a certain amount of money back if performance is judged to be unsatisfactory (based on the performance indicators mentioned in the previous section). ${ }^{12}$

\footnotetext{
12 It must be noted that the GEF addresses issues of non-compliance by requiring action plans to achieve compliance, as opposed to penalties per se, with implementing agencies being able to continue to seek GEF financing while implementing the action plan (GEF 2017). The Adaptation Fund, on the other hand, has similar measures as the GCF, such as project/program suspension for poor implementation performance, agreement termination and accreditation cancellation (Adaptation Fund 2018).
} 
Having a penalty scheme in place increases the principal's expected utility because she can use it to motivate the agent to expend a higher level of effort, thus reducing the risk of project failure and thus shifting some of the risk associated with project failure to the agent. However, the prospect of facing a penalty reduces the agent's expected utility. The agent now can face a reduction in overall compensation via the penalty, even if he expends a high level of effort, if his effort is supplanted by external factors. In the case of clawbacks, these could deter agents that are smaller and less well capitalised (and therefore are more likely to be risk averse, as discussed in Sect. 2), as they may not be willing to take on the risk of having to reimburse the donor if the project is not performing well, as a large claw-back could jeopardise their ability to remain a going concern.

Although the implementation of penalties (or the fear of facing them) incentivises greater performance by the agent, the principal needs to be careful with the amount of risk it transfers to her agent via such penalties, as it may lead him to refuse the contract (Laffont and Martimort 2009; Shavell 1979). The principal needs to structure the contract so that the agent's expected utility is still at least as high as his reservation utility (participation constraint). The contract must also ensure that the agent is motivated through a higher compensation received when he expends a high level of effort while facing a penalty (incentive compatibility constraint).

\section{Pressure from civil society organisations}

In addition to the formal accountability measures described above, informal accountability can also influence the behaviour of the principal and agent. As Romzek and Dubnick (1987) mentioned, control for accountability can also stem from informal sources, such as pressure from CSOs. Newell (2008), for instance, explored accountability and the pressure exerted by various civil society groups on key international climate change actors and found that they play an underestimated role in holding organisations to account, although this cannot be considered a substitute for formal oversight. Basak and KarlssonVinkhuyzen (2018) studied accountability issues related to the Green Climate Fund and found that CSOs exert informal pressure using various means, including via public and social media, in addition to their formal role as active observers at GCF board meetings. In the case of large international organisations providing climate change financing, such as the GCF, it is easy to imagine that CSOs target them via various means to pressure these institutions into financing projects that align with the CSO's values and objectives. In a study of environmental performance of projects funded by the World Bank, it was found that CSO pressure changed the institution's lending patterns (Buntaine 2015).

In the principal-agent relationship described in the previous sections, adding pressure from CSOs in the form of negative press and public embarrassment would provide disutility to the principal. This pressure could be due to project failure, but also due to negative side effects of the project, such as impacts on local communities or the local environment. We assume that the principal anticipates, ex ante, that the CSOs will exert pressure (even though the said pressure will only be exerted ex-post), therefore providing a reduction in her expected utility. For the principal to reach the same expected utility level, as compared to the case without CSO pressure, she has several options available.

In the face of CSO pressure, the first option the principal can take to retain her expected utility is to reduce the probability of project failure, which in this case includes negative local side effects of the project. She can do this by decreasing the project's exposure to 
negative external factors by funding a less risky project instead, thus increasing the likelihood of achieving better project results. However, CSO pressure could then lead to perverse outcomes: the new project may not provide the same benefits in terms of climate change mitigation or adaptation, or the project may offer fewer economic, social, health or environmental co-benefits (Briggs 2017). Indeed, there is a risk that CSO pressure leads to the funding of projects in areas that need it least (Birdsall and de Nevers 2012). Alternatively, she could also get the agent to put in a higher effort level by offering him a larger payment ex ante (for each unit of mitigation and/or adaptation performance he delivers, as measured by the performance indicator), which may reduce her utility if the agent's effort does not increase performance to a large enough extent ex-post. This would also lead to costlier overall project implementation. Another way to reduce the risk of project failure (in response to possible CSO pressure) is to adjust the MES, for example by including indicators that would measure the anticipated negative side effects on the local environment and communities or using indicators that have a stronger correlation with project outcomes but may be costlier to generate. Increasing the penalty for the agent's poor performance could also be used to incentivise the agent to perform better. However, the higher penalty may reduce expected utility for the agent, who may wish not to participate, as found in Shavell (1979).

The second option available to the principal is reducing the implementation cost of the project. This can be achieved by decreasing the payment offer to her agent or by reducing the MES cost for review and verification. The lower payment offer, as discussed above, may lead the agent to refuse the contract. It could also lead him to accept the contract, but to reduce his effort level, which could in turn increase the likelihood of project failure. If the principal chooses to reduce the MES review and verification cost, this may lead to insufficient project oversight.

In the case of the agent, we assume that CSO pressure will depend on the agent's size. If the agent is a smaller entity, such as a local non-governmental organisation, it may "fly under the radar" and avoid attention from CSOs, which would mean that CSO pressure would not be part of the agent's utility directly. However, if the agent is a larger or more visible organisation, it may be pressured by CSOs. This is a plausible scenario, especially for certain accredited entities under the GCF, such as HSBC, Deutsche Bank and UNDP. This assumption therefore relates to the risk preferences discussed in Sect. 2-as CSO pressure is assumed to only affect larger agents (who are assumed to be less risk averse); this pressure is not as consequential in terms of the participation constraint. In other words, anticipated CSO pressure is less likely to cause larger agents to refuse the principal's contract.

We assume that the agent anticipates, ex ante, that the CSOs will exert pressure in case of project failure or negative side effects, therefore providing a reduction in his expected utility. The agent's options to retain his expected utility in the face of increased CSO pressure (to compensate for the disutility generated by the CSO pressure) include getting paid more by the principal, reducing his cost of project implementation or reducing the penalty he could face. To get paid more, the agent could ensure to put in a high level of effort to reach high performance and therefore get paid more ex-post, which would also reduce the likelihood of project failure. Alternatively, the agent could ask for a higher payment in case of success or in case of failure (or both) to increase expected utility. Of course, the contract should still encourage the agent to put in a high level of effort. To reduce his cost of project implementation, the agent could decide to lower his cost of MES implementation via efficiency improvements or by "cutting corners" but when certain targets laid out in the MES are missed, the principal could consider this to be violation of the contract. 
We have shown in his section that CSO pressure can have positive as well as negative effects on project outcomes. Donor and agent become more aware of potential negative side effects, and the agent may choose to improve his effectiveness. However, CSO pressure may also lead to perverse outcomes as the donor may decide to fund less risky projects that have lower climate benefits. This raises issues of fairness in terms of where climate finance should be allocated, with many advocating for resources to be focused on the most at-risk and poorest countries (Pittel and Rübbelke 2013). In addition, if the agent chooses to reduce the cost of implementation by cutting corners, then CSO pressure could perversely lead to an increased risk of project failure. As such, it behoves donors to structure contracts and impose accountability measures that avoid such perverse outcomes.

\section{Conclusions and discussion}

In this paper, we have analysed the accountability relationship between a donor and a grantee in the context of financing international climate change adaptation or mitigation projects using the framework of principal-agent theory. As the donor (principal) cannot observe the actions of the grantee (agent), formal and informal accountability measures can be used to align the interests of the two parties.

As a first formal measure, the donor can implement a Monitoring and Evaluation System in which the recipient has to report on various indicators and payments are linked to the progress on these indicators. While the MES can serve to align the interests of the donor and grantee, such a system is also costly to both parties and may thereby induce an agent to turn down the contract on offer. Furthermore, the indicators should be strongly correlated with mitigation and adaptation benefits as otherwise the agent will spend disproportionate effort on actions with little relevance for the project. Poorly correlated indicators are especially problematic when the agent is highly risk averse as they may fail to incentivise him to put in a high level of effort. This makes the case against donor imposition of MESs that comprise arbitrarily selected performance indicators and supports arguments for project management approaches such as the development of "logic models" or "theories of change" to ensure there is a good match between performance indicators and project objectives (Chen 2015; Mayne 2015).

As a second formal accountability measure, penalties can influence recipient behaviour and have a positive impact on project outcomes. The penalties, which are commonplace in climate finance, were shown to help shift the risk of poor project performance from the donor to the recipient. The penalties mean that the recipient has a personal stake in the achievement of climate change mitigation and adaptation results, and this risk-sharing arrangement therefore requires a larger compensation payment in order for the agent to be willing to participate. Moreover, we have seen that this hinges upon the risk profile of the project (including the overall risk environment, which can include macroeconomic trends, fragility of the country and the strength of the institutions that the project proponent needs to work with) and the level of risk the grant recipient is willing to tolerate. As such, the donor needs to carefully consider the amount of risk she intends to impose upon her agent in the form of accountability requirements, including penalty schemes, to ensure that there is indeed a diverse set of entities willing to bid for the delivery of projects. This is especially important for projects that are to be implemented in countries where it is more difficult to operate. In those instances, donors who want to ensure diversity in implementing 
entities may want to consider reducing the grantee's risk exposure by imposing penalties and Monitoring and Evaluation Systems that do not scare off smaller agents.

CSO pressure can bring about informal accountability by modifying the behaviour of the principal and agent. CSO pressure can induce the principal and the agent to keep an eye on negative side effects of the project, for example on local communities or the local environment. It can also lead to increased effort by the agent. However, CSO pressure can also lead to perverse outcomes. CSO pressure on the donor can lead to the funding of projects with less risk of CSO pressure, yet with lower adaptation or mitigation benefits, and lead to the funding of projects where money is least needed, raising issues of fairness. Furthermore, it can increase the cost of project implementation, can decrease participation by smaller agents and can increase the likelihood of project failure. CSO pressure towards the agent can increase the risk of project failure through contract violation as the agent tries to reduce costs of MES implementation.

Putting more risk on the grantee through a penalty or CSO pressure can imply that more risk-averse agents may decide not to apply for particular projects. As larger, more capitalised parties can bear more risk from individual projects than small agents, accountability regimes have to carefully balance the amount of risk shifted from the donor to the potential recipients. As more risk for the agent may cause self-selection amongst potential recipients, the final pool of potential project implementers may eventually consist of a limited group of large organisations that could exploit its market power towards donors by asking higher fees. This also points to another recommendation: the GCF could differentiate contracts between large and small entities because larger entities can bear more risk. One could envisage offering contracts with a larger fixed wage, relative to the risk-sharing part of the contract for smaller, more risk-averse Accredited Entities.

The analysis and the discussion above describe the relationship between a single principal and a single agent. This relationship is representative of the contracting between the GCF and one of its Accredited Entities. The donor-recipient relationship is in reality much more complex and subtler than what is described in the above simplified analysis. The use of the simplified relationship serves only to isolate the specific accountability measures that we set out to analyse in order to more easily assess their potential impact. In reality, there is a "cascade" of accountability relationships in international climate change financing, with donor countries funding multilateral institutions, who in turn fund implementing partners, who then subcontract all or parts of the implementation. Other actors involved, such as project evaluators, auditors and trustees, also play an account holding role and can be influenced by CSO pressure. An area for future research would be to model such complex accountability webs using a multi-principal, multi-agent model, following Attar et al. (2010), for instance.

Our analysis also takes for granted that the principal takes her role of account holder seriously and does not hesitate to impose penalties for poor performance, for instance. This has been shown to often not be the case in practice and is one of the criticisms of using agency theory to analyse accountability issues (Schillemans and Busuioc 2015). The credibility and willingness of the principal to impose the accountability measures at her disposal are no doubt essential to the well-functioning of accountability regimes. Indeed, in a study of the accountability regimes around the GCF, Basak and Karlsson-Vinkhuyzen (2018) reported that some respondents doubt whether the GCF board will be willing to impose penalties on agents from large donor countries.

Another area for future research would be to analyse how donors could further incentivise their grant recipients for the achievement of individual outcomes (e.g. carbon sequestration, climate resilience), using an approach similar to Thiele (2010), who used a multitask 
principal-agent model to analyse how the varying abilities of an agent to deliver on certain tasks require different incentive contracts. Also, analysing the role of trust as an element that has an influence on the principal and agent over the longer term would allow us see how agents can behave to increase their chances of receiving future funding, which is likely a strong incentive for agents to perform. As Broadbent et al. (1996) argued, trust and the building of long-term relationships can lead agents to better align their interests with those of the principal. Empirical study of principal and agent objectives and the effectiveness of the measures used to align incentives should be undertaken to verify whether such extrinsic measures conflict with intrinsic motivations, as is discussed in some of the literature (Kreps 1997).

Acknowledgements We thank Sylvia Karlsson-Vinkhuyzen and Hans-Peter Weikard for useful discussions and comments and two reviewers for helping us to improve our manuscript.

\section{Compliance with ethical standards}

Conflict of interest The authors declare that they have no conflict of interest.

Open Access This article is distributed under the terms of the Creative Commons Attribution 4.0 International License (http://creativecommons.org/licenses/by/4.0/), which permits unrestricted use, distribution, and reproduction in any medium, provided you give appropriate credit to the original author(s) and the source, provide a link to the Creative Commons license, and indicate if changes were made.

\section{References}

Abbott, K. W., \& Gartner, D. (2011). The Green Climate Fund and the Future of Environmental Governance (No. 16). EARTH System Governance Working Paper. Lund and Amsterdam: Earth System Governance.

Adam, C. S., \& Gunning, J. W. (2002). Redesigning the aid contract: Donors' use of performance indicators in Uganda. World Development, 30(12), 2045-2056. https://doi.org/10.1016/S0305-750X(02)00123-7.

Adaptation Fund. (2018). Legal agreement between the adaptation fund board and implementing entity. Washington, DC: Adaptation Fund.

Adger, W. N., Arnell, N. W., \& Tompkins, E. L. (2005). Successful adaptation to climate change across scales. Global Environmental Change, 15(2), 77-86. https://doi.org/10.1016/j.gloenvcha.2004.12.005.

Anderson, J. R., \& Feder, G. (2004). Agricultural extension: Good intentions and hard realities. World Bank Research Observer, 19(1), 41-60. https://doi.org/10.1093/wbro/lkh013.

Attar, A., Campioni, E., Piaser, G., \& Rajan, U. (2010). On multiple-principal multiple-agent models of moral hazard. Games and Economic Behavior, 68(1), 376-380. https://doi.org/10.1016/j. geb.2009.07.010.

Audia, P. G., \& Greve, H. R. (2006). Less likely to fail: Low performance, firm size, and factory expansion in the shipbuilding industry. Management Science, 52(1), 83-94. https://doi.org/10.1287/ mnsc. 1050.0446.

Basak, R., \& Karlsson-Vinkhuyzen, S. I. (2018). Accountability regimes and international climate change financing: The green climate fund. Wageningen: Mimeo.

Binnendijk, A. (2000). Results based management in the development co-operation agencies: A review of experience. Paris: OECD.

Bird, N., Brown, J., \& Schalatek, L. (2011). Design challenges for the green climate fund. London: Heinrich Boll Stiftung North America, Overseas Development Institute.

Birdsall, N., \& de Nevers, M. (2012). Adaptation finance: How to get out from between a rock and a hard place (No. 001). CGD Policy Papers. Washington, DC.

Bourguignon, F., \& Sundberg, M. (2007). Aid effectiveness-Opening the black box. American Economic Review, 97(2), 316-321. 
Bourne, M., Mills, J., Wilcox, M., Neely, A., \& Platt, K. (2000). Designing, implementing and updating performance measurement systems. International Journal of Operations \& Production Management, 20(7), 754-771. https://doi.org/10.1108/01443570010330739.

Bovens, M. A. P. (2007). Analysing and assessing accountability: A conceptual framework. European Law Journal, 13(4), 447-468.

Branca, G., Tennigkeit, T., Mann, W., \& Lipper, L. (2012). Identifying opportunities for climate-smart agriculture investments in Africa. Food and Agriculture Organization of the United Nations. Rome: FAO.

Briggs, R. C. (2017). Does foreign aid target the poorest? International Organization, 71(1), 187-206. https ://doi.org/10.1017/S0020818316000345.

Broadbent, J., Dietrich, M., \& Laughlin, R. (1996). The development of principal-agent, contracting and accountability relationships in the public sector: Conceptual and cultural problems. Critical Perspectives on Accounting, 7, 259-284.

Brunner, S., \& Enting, K. (2014). Climate finance: A transaction cost perspective on the structure of state-to-state transfers. Global Environmental Change, 27, 138-143. https://doi.org/10.1016/j.gloen vcha.2014.05.005.

Buntaine, M. T. (2015). Accountability in global governance: Civil society claims for environmental performance at the World Bank. International Studies Quarterly, 59(1), 99-111. https://doi.org/10.1111/ isqu. 12145 .

Ebi, K. L., Lim, B., \& Aguilar, Y. (2004). Scoping and designing an adaptation project. Technical Paper 1. In B. Lim \& E. Spanger-Siegfried (Eds.), Adaptation policy frameworks for climate change: Developing strategies, policies and measures. New York: Cambridge University Press.

Chen, H. (2015). Practical program evaluation: Theory-driven evaluation and the integrated evaluation perspective (2nd ed.). Thousand Oaks: SAGE Publications.

Collier, P., Guillaumont, P., Guillaumont, S., \& Gunning, J. W. (1997). Redesigning conditionality. World Development, 25(9), 1399-1407.

Crainich, D., \& Eeckhoudt, L. (2008). On the intensity of downside risk aversion. Journal of Risk and Uncertainty, 36(3), 267-276. https://doi.org/10.1007/s11166-008-9037-x.

Crawford, P., \& Bryce, P. (2003). Project monitoring and evaluation: A method for enhancing the efficiency and effectiveness of aid project implementation. International Journal of Project Management, 21(5), 363-373. https://doi.org/10.1016/S0263-7863(02)00060-1.

Dixit, A. K. (2002). Incentives and organizations in the public sector: An interpretative review. Journal of Human Resources, 37(4), 696-727. https://doi.org/10.2307/3069614.

Dobrev, S. D. (2001). Revisiting organizational legitimation: Cognitive diffusion and sociopolitical factors in the evolution of Bulgarian Newspaper Enterprises, 1846-1992. Organization Studies, 22(3), 419444. https://doi.org/10.1177/07399863870092005.

Dubnick, M. (1998). Clarifying accountability: An ethical theory framework. In N. Preston \& C. Sampford (Eds.), Public sector ethics: Finding and implementing values (pp. 68-81). London: Routledge. https:// doi.org/10.4324/9780203063941.

Ebrahim, A. (2003a). Accountability in practice: Mechanisms for NGOs. World Development, 31(5), 813829. https://doi.org/10.1016/S0305-750X(03)00014-7.

Ebrahim, A. (2003b). Making sense of accountability: Conceptual perspectives for northern and southern nonprofits. Nonprofit Management and Leadership, 14(2), 191-212. https://doi.org/10.1002/nml.29.

Engle, N. L. (2011). Adaptive capacity and its assessment. Global Environmental Change, 21(2), 647-656. https://doi.org/10.1016/j.gloenvcha.2011.01.019.

Feltham, G. A., \& Xie, J. (1994). Performance measurement congruity and diversity in congruity principal/ agent relations. The Accounting Review, 69(3), 429-453.

Gailmard, S. (2014). Accountability and principal-agent theory. In M. Bovens, R. E. Goodin, \& T. Schillemans (Eds.), Oxford handbook of accountability (pp. 90-105). Oxford: Oxford University Press. https ://doi.org/10.1093/oxfordhb/9780199641253.013.0016.

GCF. (2015). DECISION B.11/10—Agenda item 15: Initial monitoring and accountability framework for accredited entities. Songdo International Business District: GCF.

GCF. (2017). Accreditation to the Green Climate Fund. Songdo International Business District: GCF.

GEF. (2012). Procedure: Accreditation of GEF project agencies. Washington, DC: Global Environment Facility.

GEF. (2017). Policy on monitoring agency compliance with GEF policies. Washington, DC: Global Environment Facility.

Gundimeda, H., \& Guo, Y. (2003). Undertaking emission reduction projects: Prototype carbon fund and clean development mechanism. Economic and Political Weekly, 38(41), 4331-4337. https://doi. org/10.2307/4414134. 
Hall, N. (2017). What is adaptation to climate change? Epistemic ambiguity in the climate finance system. International Environmental Agreements: Politics, Law and Economics, 17(1), 37-53. https://doi. org/10.1007/s10784-016-9345-6.

Haque, M. A. (2014). Accountability for public expenditure in Bangladesh: The principal-agent problem and role of the office of the comptroller and auditor general. Asia Pacific Journal of Public Administration, 36(4), 249-260. https://doi.org/10.1080/23276665.2014.979018.

Hawkins, D. G., Lake, D. A., Nielson, D. L., \& Tierney, M. J. (Eds.). (2006). Delegation and agency in international organizations. Cambridge: Cambridge University Press.

Heal, G., \& Chichilnisky, G. (Eds.). (2000). Environmental markets: Equity and efficiency. New York: Columbia University Press.

Holzapfel, S. (2016). Boosting or hindering aid effectiveness? An assessment of systems for measuring donor agency results. Public Administration and Development, 36(February), 3-19. https://doi. org/10.1002/pad.1749.

Jensen, C., \& Meckling, H. (1976). Theory of the firm : Managerial behavior, agency costs and ownership structure. Journal of Financial Economics, 3(December), 305-360. https://doi.org/10.1016/0304405x(76)90026-X.

Kimball, M. S. (1990). Precautionary saving in the small and in the large. Econometrica, 58(1), 53-73.

Kluvers, R., \& Tippett, J. (2010). Mechanisms of accountability in local government: An exploratory study. International Journal of Business and Management, 5(7), 46-53.

Kreps, D. M. (1997). Intrinsic motivation and extrinsic incentives. The American Economic Review, 87(2), 359-364.

Laffont, J.-J., \& Martimort, D. (2009). The theory of incentives: The principal-agent model. Princeton: Princeton University Press.

Ligon, J. A., \& Thistle, P. D. (2013). Background risk in the principal-agent model. The Geneva Risk and Insurance Review, 38(2), 115.

Mas-Colell, A., Whinston, M. D., \& Green, J. R. (1995). Microeconomic theory (1st ed.). Oxford: Oxford University Press.

Mayne, J. (2015). Useful theory of change models. Canadian Journal of Program Evaluation, 30(2), 119142. https://doi.org/10.3138/cjpe.230.

McAfee, P., \& McMillan, J. (1986). Bidding for contracts: A principal-agent analysis. The Rand Journal of Economics, 17(3), 326-338.

Michaelowa, A., \& Michaelowa, K. (2011). Coding error or statistical embellishment? The political economy of reporting climate aid. World Development, 39(11), 2010-2020.

Milner, H. V. (2006). Why multilateralism? Foreign aid and domestic principal-agent problems. In D. G. Hawkins, D. A. Lake, D. L. Nielson, \& M. J. Tierney (Eds.), Delegation and agency in international organizations (pp. 107-139). Cambridge: Cambridge University Press. https://doi.org/10.1017/cbo97 80511491368.005.

Mitchell, R. B., \& Parson, E. A. (2001). Implementing the climate change Regime's clean development mechanism. Journal of Environment and Development, 10(2), 125-146.

Modica, S., \& Scarsini, M. (2005). A note on comparative downside risk aversion. Journal of Economic Theory, 122(2), 267-271. https://doi.org/10.1016/j.jet.2004.06.008.

Morra-Imas, L. G., \& Rist, R. C. (2009). The road to results: Designing and conducting effective development evaluations. Washington, DC: The International Bank for Reconstruction and Development/The World Bank. https://doi.org/10.1596/978-0-8213-7891-5.

Mosley, P., Hudson, J., \& Verschoor, A. (2004). Aid, poverty reduction and the "New Conditionality". The Economic Journal, 114(June), 217-244.

Newell, P. (2008). Civil society, corporate accountability and the politics of climate change. Global Environmental Politics, 8(3), 122-153. https://doi.org/10.1162/glep.2008.8.3.122.

OECD Development Assistance Committee. (2014). Development assistance and approaches to risk in fragile and conflict affected states. Paris: OECD Publishing.

Pickering, J., Betzold, C., \& Skovgaard, J. (2017). Special issue: managing fragmentation and complexity in the emerging system of international climate finance. International Environmental Agreements: Politics, Law and Economics, 17(1), 1-16. https://doi.org/10.1007/s10784-016-9349-2.

Pittel, K., \& Rübbelke, D. (2013). International climate finance and its influence on fairness and policy. World Economy, 36(4), 419-436. https://doi.org/10.1111/twec.12029.

Romzek, B. S., \& Dubnick, M. J. (1987). Accountability in the public sector: Lessons from the challenger tragedy. Public Administration Review, 47(3), 227-238. https://doi.org/10.2307/975901.

Schiavo-Campo, S. (1999). "Performance" in the public sector. Asian Journal of Political Science, 7(2), 75-87. https://doi.org/10.1080/02185379908434148. 
Schillemans, T., \& Busuioc, M. (2015). Predicting public sector accountability: From agency drift to forum drift. Journal of Public Administration Research and Theory, 25(1), 191-215. https://doi.org/10.1093/ jopart/muu024.

Shavell, S. (1979). Risk sharing and incentives in the principal and agent relationship. The Bell Journal of Economics, 10(1), 55-73. https://doi.org/10.2307/3003319.

Shaw, K. L. (1996). An empirical analysis of risk aversion and income growth. Journal of Labor Economics, $14(4), 626-653$.

Sinclair-Desgagné, B., \& Spaeter, S. (2017). Incentive contracts and downside risk sharing. Paris: CIRANO, CNRS.

Soudry, O. (2008). A principal-agent analysis of accountability in public procurement. In G. Piga \& K. V. Thai (Eds.), Advancing public procurement: Practices, innovation and knowledge sharing (pp. 432451). Boca Raton, FL: PrAcademics Press.

Steinberg, R. S. (2010). Principal-agent theory and nonprofit accountability. In T. Hopt \& K. J. Von Hippelpp (Eds.), Comparative corporate governance of non-profit organizations (pp. 73-126). Cambridge: Cambridge University Press. https://doi.org/10.1017/cbo9780511712128.006.

Thiele, V. (2010). Task-specific abilities in multi-task principal-agent relationships. Labour Economics, 17(4), 690-698. https://doi.org/10.1016/j.labeco.2009.12.003.

UNFCCC. (2011). Report of the conference of the parties on its sixteenth session, held in Cancun from 29 November to 10 December 2010. Decision 1/CP.16.

UNFCCC. (2014). FOCUS: Climate finance. Bonn: United Nations Framework Convention on Climate Change.

UNFCCC. (2015). Adoption of the Paris agreement. Paris: United Nations Framework Convention on Climate Change. https://unfccc.int/resource/docs/2015/cop21/eng/109r01.pdf. Accessed 7 Feb 2017.

UNFCCC. (2018). Report of the green climate fund to the conference of the parties and guidance to the green climate fund. Katowice: United Nations Framework Convention on Climate Change.

van Kerkhoff, L., Ahmad, I. H., Pittock, J., Steffen, W., Ahmad, I. H., Pittock, J., et al. (2011). Designing the green climate fund: How to spend \$100 billion sensibly. Environment Magazine, 53(3), 18-31.

Van Kersbergen, K., \& Van Waarden, F. (2004). "Governance" as a bridge between disciplines: crossdisciplinary inspiration regarding shifts in governance and problems of governability, accountability and legitimacy. European Journal of Political Research, 43(2), 143-171. https://doi.org/10.111 1/j.1475-6765.2004.00149.x.

Winters, M. S. (2010). Accountability, participation and foreign aid effectiveness. International Studies Review, 12, 218-243.

World Bank. (2004). World development report 2004: Making services work for poor people. Washington, DC: World Bank. https://doi.org/10.1093/jae/ejh019.

Publisher's Note Springer Nature remains neutral with regard to jurisdictional claims in published maps and institutional affiliations. 